\title{
An Unusual Case of Mouth Opening Limitation Caused by Bilateral Coronoid Process Hyperplasia: A Case Report
}

\author{
Farzin Sarkarat ${ }^{1 \#}$, Roozbeh Kahali ${ }^{2}$
}

1. Associate Professor, Oral and Maxillofacial Surgery Dept, Crania maxillofacial Research Center, Tehran Medical Science , Islamic Azad University , Tehran, Iran

2.Assistant Professor, Oral and Maxillofacial Surgery Dept,Tehran Medical Science, Islamic Azad University, Tehran, Iran

\begin{tabular}{l}
\hline ARTICLE INFO \\
\hline Article Type \\
Original Article \\
\hline Article History \\
Received: Sep 2018 \\
Accepted: Oct 2018 \\
ePublished: Nov 2018
\end{tabular}

\section{Keywords:}

Coronoid Process,

Hyperplasia,

Trismus,

Temporomandibular Joint

Disorders

\begin{abstract}
Background: Coronoid process hyperplasia is the enlargement of the coronoid processes that may lead to their impingement on the zygomatic arch and limitation of mouth opening. It can be unilateral or bilateral and usually affects men in the second decade of life. The etiology of coronoid process hyperplasia is unknown. The aim of treatment is to restore the mouth opening, and the only available treatment is surgery. Intraoral coronoidectomy has been suggested as the treatment of choice. Although the immediate increase in jaw mobility is gained after surgery, proper postoperative rehabilitation and physical therapy are necessary to maintain the mouth opening range. Case Presentation: This case report is about a 40 -year-old male patient with bilateral mandibular coronoid process hyperplasia treated with coronoidectomy followed by intensive physical therapy.

Conclusion: Coronoid process hyperplasia is a rare condition interfering with the patient's normal mouth opening. Dentists should consider this diagnosis in case of painless mouth opening limitations.
\end{abstract}




\section{Introduction:}

One of the functional disorders of the temporomandibular joint (TMJ) is the mouth opening limitation. The normal mandibular range of motion and mouth opening is generally accepted to be $35 \mathrm{~mm}$ to $45 \mathrm{~mm}$, which varies with stature, gender, etc. ${ }^{(1,2)}$

A limited mandibular range of motion results from intracapsular or extracapsular disorders. Intracapsular disorders may include disc displacement without reduction, calcified bodies within the joint space, fibrosis, fracture, ankylosis, and tumors. Extracapsular disorders include dysfunction of the muscles involved in mandibular elevation, hypertrophy of the coronoid processes, fractures, and capsular scarring. ${ }^{(3)}$

Coronoid process hyperplasia is the enlargement of the coronoid processes, which may lead to their impingement on the zygomatic arch. ${ }^{(3)}$ Coronoid process hyperplasia is a congenital or developmental painless TMJ disorder with a progressive decrease in mouth opening, which is usually bilateral. ${ }^{(4)}$ It often appears during puberty and predominantly affects males. Masticatory muscle fibrosis usually occurs secondarily to hypofunction. Usually, there is facial asymmetry in unilateral cases. ${ }^{(3)}$ Rowe has described the most common symptoms of bilateral coronoid process hyperplasia as painless mouth opening limitation with no occlusal abnormality, which is caused by infringement of the coronoid process on the $\mathrm{zy}$ gomatic arch. ${ }^{(5)}$

The panoramic view, oblique posterioranterior view, and modified Town's view for condyles are the most used conventional radiographic imaging techniques for evaluation of the coronoid processes. Computed tomography (CT) with three-dimensional (3D) reconstructions and cone-beam CT (CBCT) are the best and most accurate techniques that can be used today. ${ }^{(6)}$

This case report is about a patient with bilateral mandibular coronoid process hyperplasia treated with coronoidectomy followed by intensive physical therapy.

\section{Case Presentation:}

A 40-year-old male patient with good general health presented for treatment to our clinic in October 2017, with a complaint of painless mouth opening limitation. In the clinical examination, there was no tenderness upon muscle and TMJ palpation. The cranial nerves were intact. The patient reported no history of facial or cranial trauma. He had never undergone any type of dental treatment because of the mouth opening limitation. The overall shape of the face was symmetric, and the patient had a symmetric maximum mouth opening with $15 \mathrm{~mm}$ of inter-incisal distance and no joint sounds present. Right and left lateral movements were $4 \mathrm{~mm}$ each. The maximum mouth opening did not increase with assisted mouth opening, and no muscle stiffness was sensed. Based on the above, the initial clinical diagnostic impression was some kind of bony mechanical engagement, and images were requested. The panoramic radiograph showed the bilateral enlargement of the coronoid processes (Figure 1), which was confirmed by CBCT (Figure 2) to be bilateral coronoid process hyperplasia.

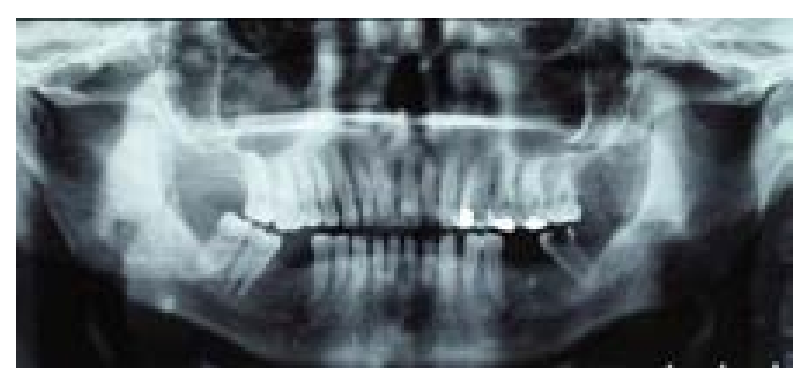

Figure 1. Bilateral enlargement of the coronoid processes (panoramic view) 


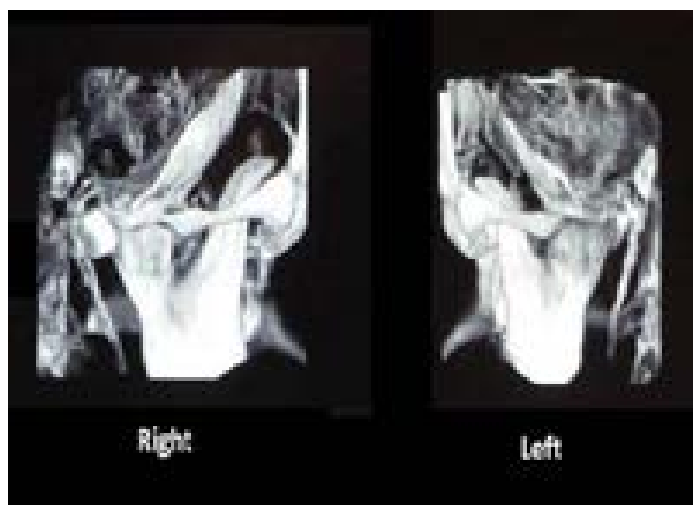

Figure 2. Bilateral enlargement of the coronoid processes (cone-beam computed tomography (CBCT) view with three-dimensional (3D) reconstruction)

In the operating room, the patient was intubated via awake nasal intubation technique using fiberoptic equipment. Under general anesthesia, bilateral intraoral coronoidectomy was performed using a reciprocating saw (Figures 3 and 4), and the heterotopic bone was removed (Figure 5).

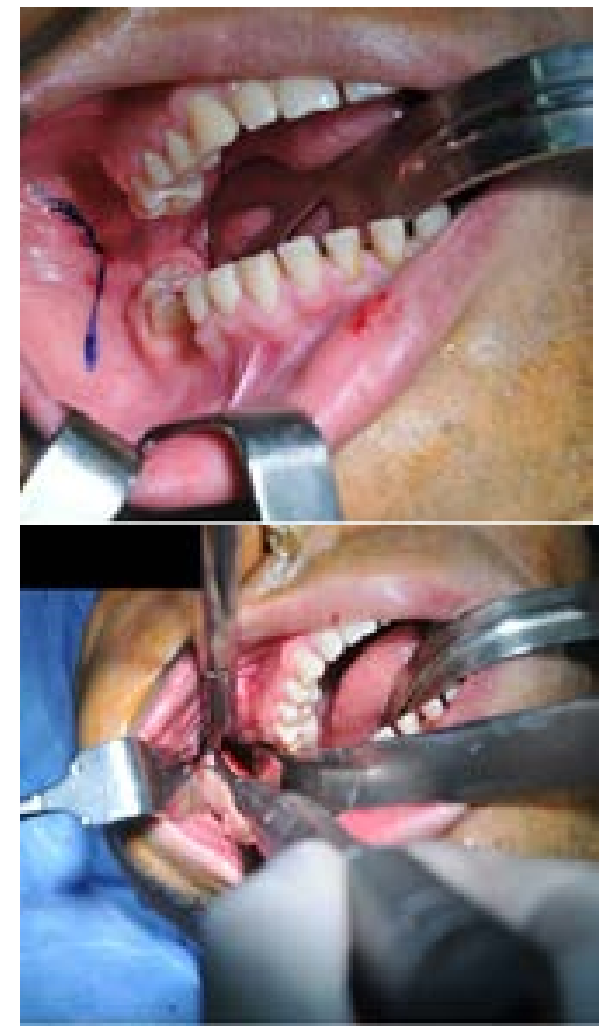

Figure 3. Right side coronoidectomy using a reciprocating saw
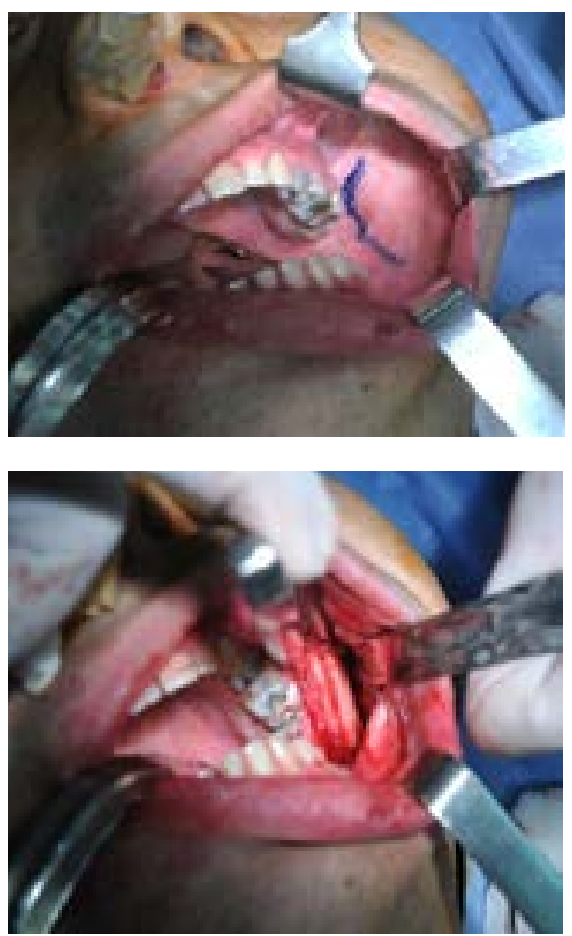

Figure 4. Left side coronoidectomy using a reciprocating saw

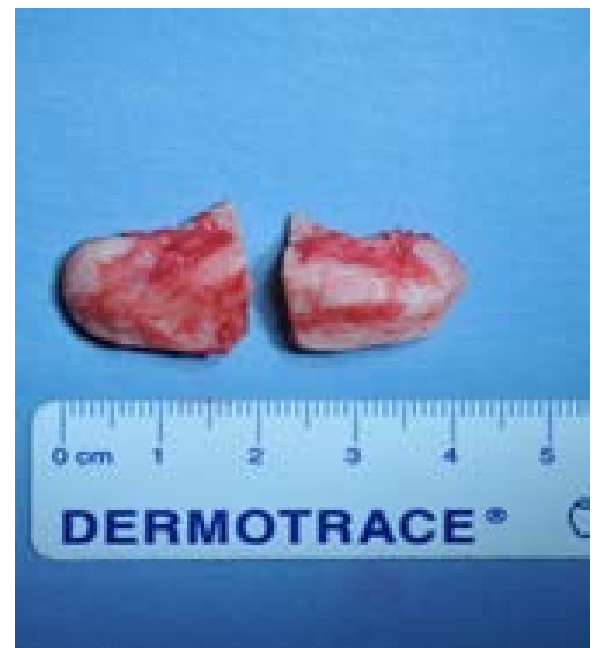

Figure 5. Removal of the heterotopic bone of the coronoid processes 


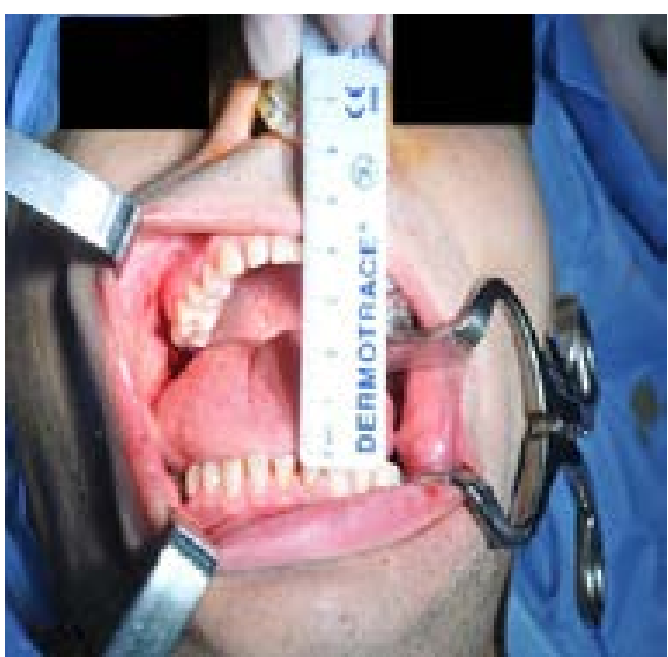

Figure 6. Immediate postoperative maximum mouth opening in the operating room

Immediately after surgery, the maximum mouth opening increased to $38 \mathrm{~mm}$ in the operating room (Figure 6). Physical therapy was initiated two weeks postoperatively to help the recovery of the mandibular normal range of motion by stretching the masticatory muscles and intra-capsular fibrosis created due to years of mandibular hypofunction. After 6 months, the patient had $35 \mathrm{~mm}$ of mouth opening and left and right lateral movements of $7 \mathrm{~mm}$ each without any pain or TMJ sounds (Figure 7).
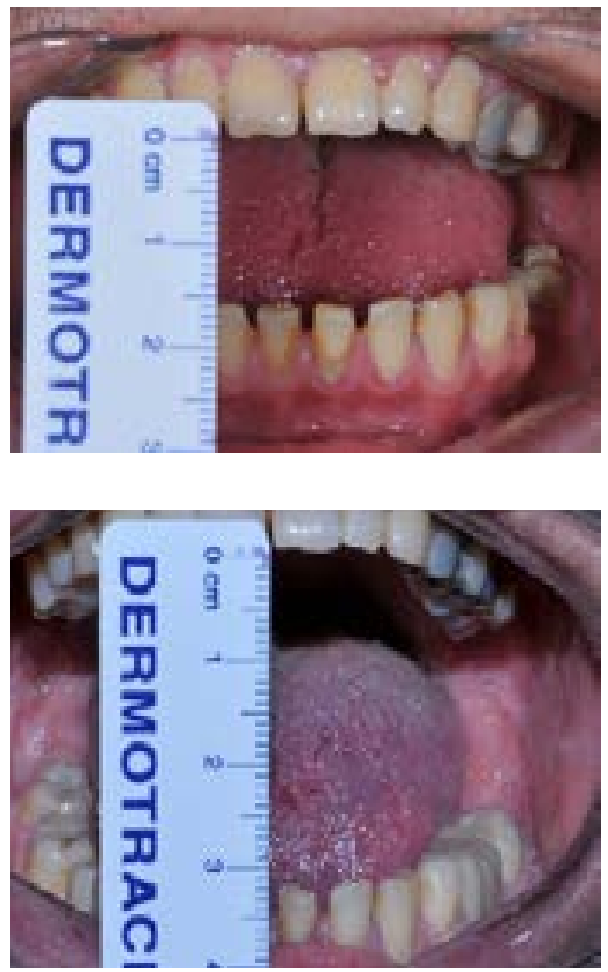

Figure 7. Maximum mouth opening range before and 6 months after surgery

\section{Discussion:}

The most common causes of mouth opening limitation are temporomandibular disorders (TMD) which are characterized by restrictions, deviations, and hypomobility. ${ }^{(7,8)}$ Coronoid process hyperplasia is another cause of mouth opening limitation; it was described for the first time in 1853 by Von Langenbeck. ${ }^{(9)}$ Since then, unilateral and bilateral cases have been described in both men and women although bilateral cases are more frequent in men. It has been reported that coronoid process hyperplasia usually affects men in the second decade of life. ${ }^{(3,10)}$ Because of its uncommonness, it is usually overlooked or misdiagnosed. This is especially true in unilateral cases which are usually caused by anterior disc displacement without reduction ${ }^{(11)}$ although one of the main characteristics of anterior disc displacement is pain, which is not common in coronoid process hyperplasia.

Mandibular hypomobility can lead to secondary problems such as malnutrition, speech problems, poor oral hygiene, dental problems, facial deformity and asymmetry, masticatory muscle atrophy, and psychosocial problems. ${ }^{(12,13)}$

The etiology of coronoid process hyperplasia is unknown. Hyperactivity of the temporalis muscle is one of the theories that is based on the reactive elongation response of the coronoid process to the extreme forces exerted by the muscle. ${ }^{(14,15)}$ Because coronoid process hyperplasia is more common in young men, endocrine stimuli may contribute to the development of this condition. ${ }^{(5)}$ A history of trauma may also be associated with this condition. (16) Genetic components and familial factors are also involved in coronoid process hyperplasia. ${ }^{(17)}$

The easiest and most affordable radiographic examination for this condition is panoramic radiography which depicts a good overall view of the mandible and the coronoid processes. ${ }^{(7)}$ After the diagnosis is confirmed, CBCT can be ordered for better detailed $3 \mathrm{D}$ evaluation of the region.

The main aim of treatment is to restore mouth opening by resolving the mechanical engagements in a stable and long-term manner. The only treatment is surgery. Most authors have suggested intraoral coronoidectomy as the treatment of 
choice, ${ }^{(3,18-20)}$ which decreases facial nerve injury and avoids extraoral scarring. The submandibular approach has also been proposed for cases with zygomatic-coronoid ankylosis. ${ }^{(21)}$ In case of a very long coronoid process, the coronal approach has also been suggested. ${ }^{(22,23)}$

Although an immediate increase in jaw mobility is gained after surgery, proper postoperative rehabilitation and physical therapy are necessary to maintain the mouth opening range; this has been emphasized by many authors. ${ }^{(10,18,22)}$ Mouth opening can become limited again by fibrosis formation secondary to hematoma in the area. ${ }^{(3,24)}$ McLoughlin et al have suggested inadequate rehabilitation as a possible cause of the recurrence of mouth opening limitation. ${ }^{(3)}$

\section{Conclusion:}

Coronoid process hyperplasia is a rare condition interfering with the patient's normal mouth opening. Dentists should consider this diagnosis in case of painless mouth opening limitations.

Conflict of interest: The authors declare that they do not have any conflict of interest.

Source of funding: The study was self-funded by the authors.

\section{References:}

1. Stegenga B, de Bont LG, de Leeuw R, Boering G. Assessment of mandibular function impairment associated with temporomandibular joint osteoarthrosis and internal derangement. J Orofac Pain. 1993 Spring;7(2):183-95.

2. Szentpétery A. Clinical utility of mandibular movement ranges. J Orofac Pain. 1993 Spring;7(2):163-8.

3. McLoughlin PM, Hopper C, Bowley NB. Hyperplasia of the mandibular coronoid process: an analysis of 31 cases and a review of the literature. $\mathrm{J}$ Oral Maxillofac Surg. 1995 Mar;53(3):250-5.

4. de Leeuw R. American Academy of Orofacial Pain: Guidelines for Assessment, Diagnosis, and Management. 4th ed. Chicago: Quintessence Publishing Co, Inc., 2008:28.

5. Rowe NL. Bilateral developmental hyperplasia of the mandibular coronoid process: a report of two cases. Br J Oral Surg. 1963 Nov;1:90-104.

6. Izumi M, Isobe M, Toyama M, Ariji Y, Gotoh M,
Naitoh M, et al. Computed tomographic features of bilateral coronoid process hyperplasia with special emphasis on patients without interference between the process and the zygomatic bone. Oral Surg Oral Med Oral Pathol Radiol Endod. 2005 Jan;99(1):93-100.

7. Gross M, Gavish A, Calderon S, Gazit E. The coronoid process as a cause of mandibular hypomobility--case reports. J Oral Rehabil. 1997 Oct;24(10):776-81.

8. Celic R, Jerolimov V, Knezovic Zlataric D. Relationship of slightly limited mandibular movements to temporomandibular disorders. Braz Dent J. 2004;15(2):151-4.

9. Von Langenbeck B. Angeborene kleinheit der unterkiefer. Langenbeck's Archiv. 1861;1:451-5. 10. Isberg A, Isacsson G, Nah KS. Mandibular coronoid process locking: a prospective study of frequency and association with internal derangement of the temporomandibular joint. Oral Surg Oral Med Oral Pathol. 1987 Mar;63(3):275-9.

11. Capote A, Rodríguez FJ, Blasco A, Muñoz MF. Jacob's disease associated with temporomandibular joint dysfunction: a case report. Med Oral Patol Oral Cir Bucal. 2005 May-Jul;10(3):210-4. 12. Galiè M, Consorti G, Tieghi R, Denes SA, Fainardi E, Schmid JL, et al. Early surgical treatment in unilateral coronoid hyperplasia and facial asymmetry. J Craniofac Surg. 2010 Jan;21(1):129-33.

13. Jaskolka MS, Eppley BL, van Aalst JA. Mandibular coronoid hyperplasia in pediatric patients. J Craniofac Surg. 2007 Jul;18(4):849-54.

14. Zhong SC, Xu ZJ, Zhang ZG, Zheng YH, Li TX, Su K. Bilateral coronoid hyperplasia (Jacob disease on right and elongation on left): report of a case and literature review. Oral Surg Oral Med Oral Pathol Oral Radiol Endod. 2009 Mar;107(3):e64-7.

15. Lyon LZ, Sarnat BG. Limited opening of the mouth caused by enlarged coronoid processes: report of case. J Am Dent Assoc. 1963 Nov;67:64450.

16. Tucker MR, Guilford WB, Howard CW. Coronoid process hyperplasia causing restricted opening and facial asymmetry. Oral Surg Oral Med Oral Pathol. 1984 Aug;58(2):130-2. 
17. York BV, Cockerham S. Bilateral hyperplasia of the coronoid processes in siblings. Oral Surg Oral Med Oral Pathol. 1983 Dec;56(6):584-5.

18. Gerbino G, Bianchi SD, Bernardi M, Berrone S. Hyperplasia of the mandibular coronoid process: long-term follow-up after coronoidotomy. J Craniomaxillofac Surg. 1997 Jun;25(3):169-73.

19. Mulder CH, Kalaykova SI, Gortzak RA. Coronoid process hyperplasia: a systematic review of the literature from 1995. Int J Oral Maxillofac Surg. 2012 Dec;41(12):1483-9.

20. Ramalho-Ferreira G, Faverani LP, Fabris AL, Pastori CM, Magro-Filho O, Ponzoni D, et al. Mandibular movement restoration through bilateral coronoidectomy by intraoral approach. J Craniofac Surg. 2011 May;22(3):988-91.

21. Ostrofsky MK, Lownie JF. Zygomatico-coronoid ankylosis. J Oral Surg. 1977 Sep;35(9):7524.

22. Hernández-Alfaro F, Escuder O, Marco V. Joint formation between an osteochondroma of the coronoid process and the zygomatic arch (Jacob disease): report of case and review of literature. J Oral Maxillofac Surg. 2000 Feb;58(2):22732.

23. Hayter JP, Robertson JM. Surgical access to bilateral coronoid hyperplasia using the bicoronal flap. Br J Oral Maxillofac Surg. 1989 Dec;27(6):487-93.

24. Gibbons AJ, Abulhoul S. Use of a Therabite appliance in the management of bilateral mandibular coronoid hyperplasia. Br J Oral Maxillofac Surg. 2007 Sep;45(6):505-6. 